\title{
MAPEAMENTO DO RUÍDO AMBIENTAL NO CAMPUS BURITIS I DO CENTRO UNIVERSITÁRIO NEWTON PAIVA
}

Guilherme Oliveira Teixeira de Carvalho - guilhermeotc@ hotmail.com

Centro Universitário Newton Paiva

Isabella Costa Rodrigues da Cunha - isabellacostarodrigues@ hotmail.com Centro Universitário Newton Paiva

Marcos Vinícius Ribeiro - marcos.ribeiro@newtonpaiva.br

Centro Universitário Newton Paiva 


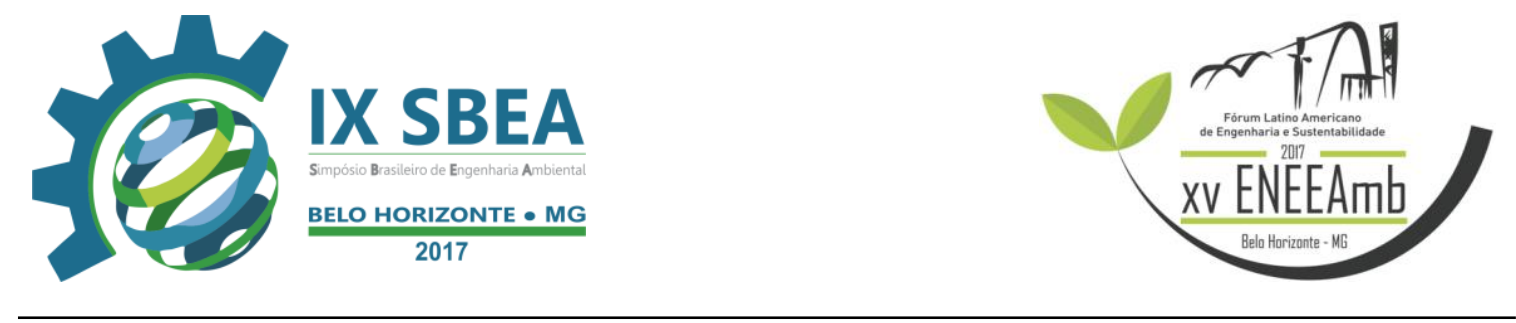

\section{RESUMO}

A presença da poluição sonora em ambientes urbanos é considerada um problema grave de saúde pública mundial, que tem contribuído para o aumento de várias doenças relacionadas à audição humana. Nas escolas, os alunos são os maiores influenciados pelo excesso deste poluente, prejudicando seu processo de aprendizagem ao longo do tempo. Este trabalho tem o objetivo principal avaliar os níveis de ruído do campus Buritis I, da faculdade Centro Universitário Newton Paiva, localizado na regional oeste da cidade de Belo Horizonte, Minas Gerais (MG). Para isso, foram escolhidos nove pontos de amostragem espalhados pelos principais setores deste campus. Com o auxílio do decibelímetro digital, foi feita a mensuração do ruído nos três turnos diferentes (manhã, tarde e noite) durante três dias da semana. Os resultados mostraram que o nível de pressão sonora é mais acentuado durante a noite, visto que há um aumento considerável no fluxo de veículos e pessoas. A elaboração do mapa acústico foi baseada na média de cada medição e constatou-se que as áreas da lanchonete e das duas portarias do prédio central foram as que apresentaram maiores níveis de ruído. Logo, estas áreas ultrapassaram o limite do período noturno estabelecidas pela legislação municipal 9505/08 de Belo Horizonte/MG ou chamada Lei do Silêncio. Por causa disso, é extremamente necessário implantar um plano de melhorias acústicas como educação no trânsito e de convivência entre as pessoas.

Palavras-chave: Avaliação de ruído, Mapa acústico, Ruído ambiental, Poluição sonora.

\section{INTRODUÇÃO/OBJETIVOS}

A Organização Mundial da Saúde (OMS) estima-se que haja mais de 50\% da população mundial vivendo em áreas urbanas desde o início do século XXI. Os dados do último censo demográfico realizado pelo IBGE em 2010 indicam que 84,36\% da população brasileira vivem em áreas urbanas e isso reflete significativamente na poluição sonora de nossas cidades.

O ruído é um som sem harmonia, em geral de conotação negativa, comum em grandes centros urbanos e sua geração é causada por diversas fontes principalmente 


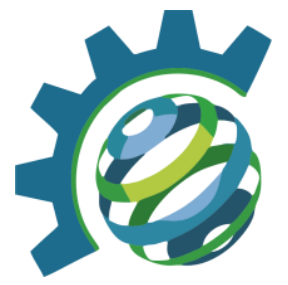

pelos meios de transporte, indústrias e canteiros de obras (CANTIERI, 2010 e BISTAFA, 2006).

Nagem (2004) mostra que o excesso de ruído causa diversos danos à saúde humana como surdez temporária ou permanente, irritabilidade, diminuição do desempenho e/ou da concentração, stress, agressividade, e até mesmo interferência na comunicação. Em razão disso, os números de reclamações por parte da população devido ao incômodo gerada por este poluente aumentam com o passar dos anos nas cidades brasileiras.

Para um bom desempenho no processo de aprendizagem em ambientes escolares é fundamental que haja uma relação harmoniosa com baixos níveis de ruído. Pimentel et. al. (2016) mostra que no Brasil são regulamentadas leis e normas que fixam valores em decibéis $(\mathrm{dB})$ para o conforto acústico. O nível aceitável para as salas de aula em instituições de ensino varia entre 40 a $50 \mathrm{~dB}$.

Porém, os níveis de ruído em ambientes escolares geralmente ultrapassam estes valores aceitáveis tornando-se um ambiente propício a interferências negativas para a saúde dos alunos, professores e da comunidade do entorno. O objetivo deste trabalho foi avaliar o nível de pressão sonora para elaborar o mapa de ruído do campus Buritis I do Centro Universitário Newton Paiva localizado no município de Belo Horizonte/MG visando melhoria da qualidade ambiental.

\section{METODOLOGIA}

\subsection{Caracterização da área de estudo}

A área de estudo (Figura 1) abrange a instituição de ensino Centro Universitário Newton Paiva, campus Buritis I, situada nas coordenadas geográficas 1957’58'’ de latitude sul e $43^{\circ} 57^{\prime} 47^{\prime}$ ' de longitude oeste, localizado na Rua José Cláudio Rezende, 420, bairro Estoril, na regional oeste da cidade de Belo Horizonte, Minas Gerais. 

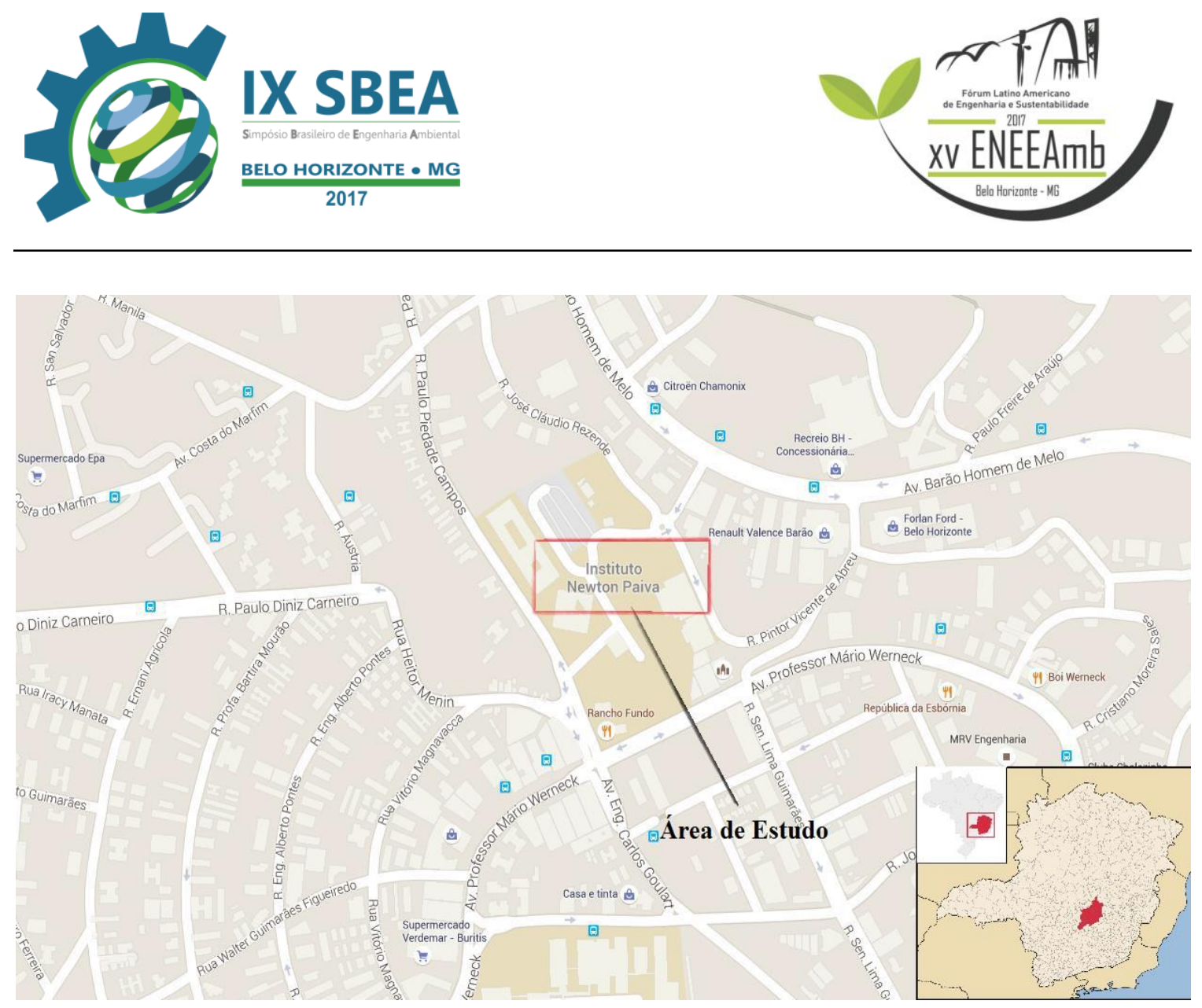

Figura 1 - Mapa de localização do Centro Universitário Newton Paiva (Campus Buritis I)

Fonte: Disponível em: <https://www.google.com.br/maps>. Acesso em: 21 nov. 2016.

\subsection{Materiais e Métodos}

O presente trabalho configura-se como uma pesquisa de campo em que foi mensurado o nível de pressão sonora, com o auxílio do decibelímetro digital MSL1325A da marca Minipa, em 9 pontos de amostragem espalhados nos principais setores do terreno da área de estudo. A pesquisa ocorreu em 3 dias diferentes da semana do mês de maio de 2016 e durante os horários das aulas além do intervalo entre elas nos períodos da manhã, tarde e noite.

A figura 2 representa o mapa de localização dos pontos de amostragem escolhidos. A linha tracejada, na cor azul, mostra os limites do terreno do campus Buritis I, enquanto a cor laranja mostra os limites do prédio central e as linhas contínuas, na cor amarelo e preta, as principais ruas adjacentes.

Antes de efetuar as mensurações do nível de pressão sonora, foi realizada a calibração do decibelímetro. Ao ligar este equipamento foram definidos alguns ajustes utilizando-se no modo $S L O W$, nível de ponderação A e também a seleção da faixa de 40 

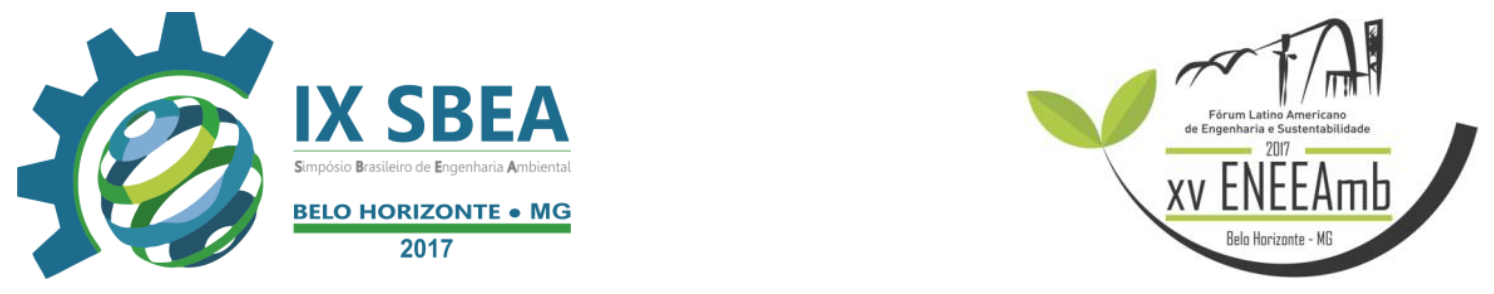

dB até $70 \mathrm{~dB}$ (durante a manhã e tarde) e $60 \mathrm{~dB}$ até $90 \mathrm{~dB}$ (durante a noite). Depois dos ajustes, foi feito um registro dos valores lidos de cinco em cinco segundos, totalizando 30 leituras. Estes procedimentos foram realizados em todos os pontos de amostragem.

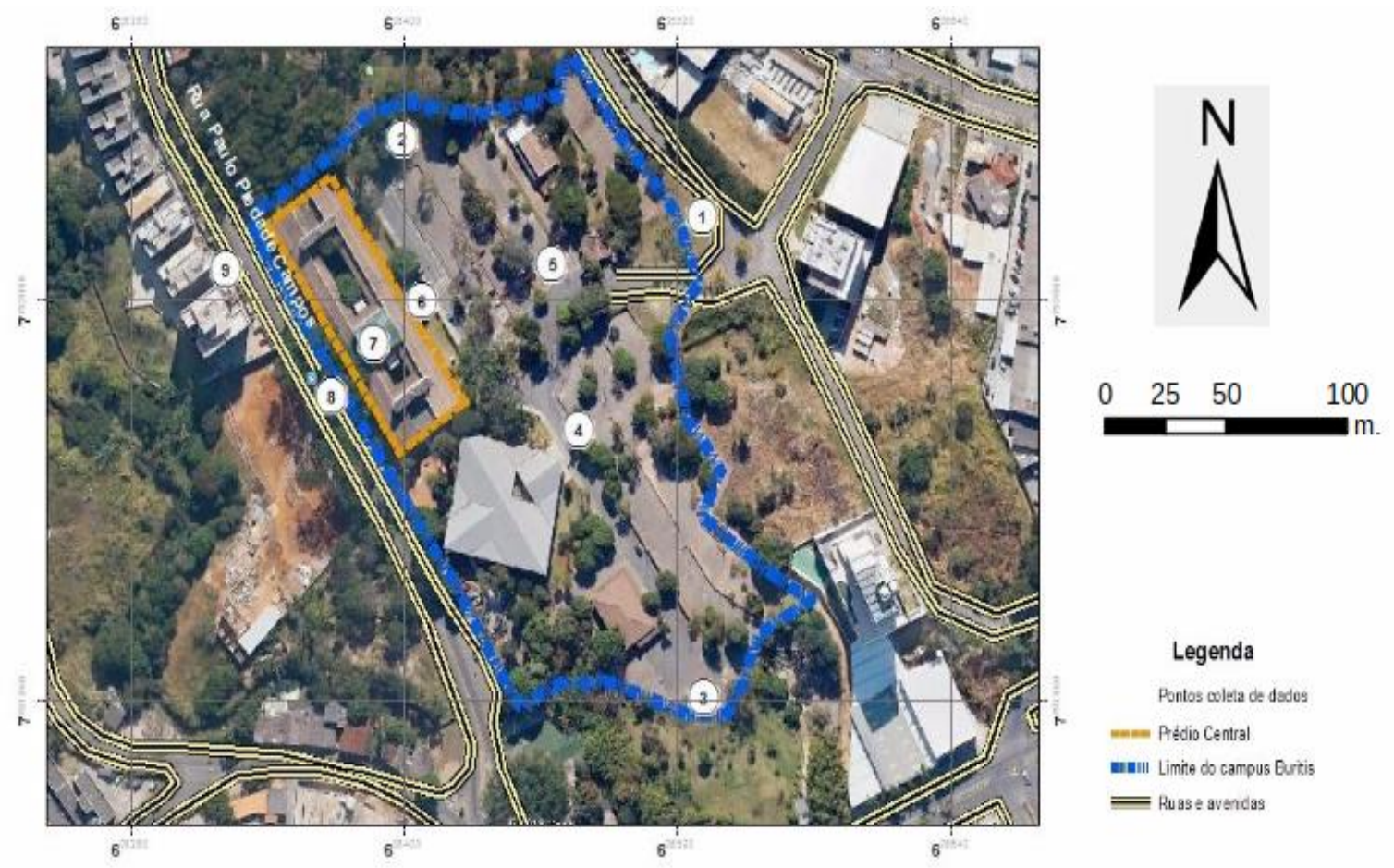

Figura 2 - Mapa de localização dos pontos de amostragem

\section{RESULTADOS E DISCUSSÃO}

Inicialmente, foi calculada a média aritmética das 30 leituras registradas pelo decibelímetro em todas as mensurações de ruído. O Gráfico 01 representa os resultados de todos os pontos de amostragem no período da manha. Os limites de tolerância (LT) se referem aos limites estabelecidos pela lei do silêncio em cada período do dia (BELO HORIZONTE, Lei 9505, de 28 de janeiro 2008).

No período da manhã, observa-se que o ponto de amostragem 07 (área da lanchonete) foi um dos mais impactantes e ultrapassou a média estabelecida pela Lei do Silêncio de $70 \mathrm{~dB}(\mathrm{~A})$, pelo motivo de ser um setor do campus Buritis I ser muito frequentado por diversas pessoas durante todo o dia, principalmente no intervalo das aulas. Os pontos 08 e 09, localizados próximos a Rua Paulo Piedade Campos, número 420, apresentou-se um tráfico mais intenso de veículos maior no final da aula do 


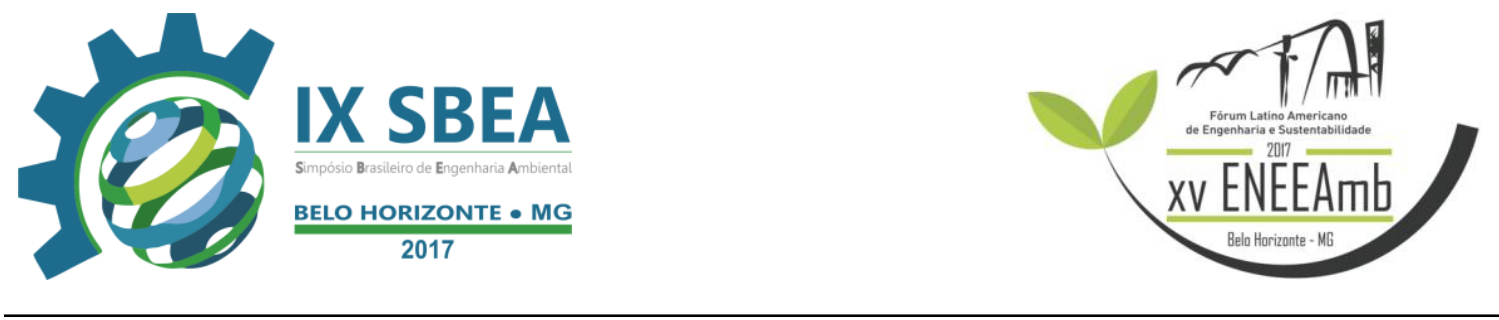

período da manhã, após as $11 \mathrm{~h} 15 \mathrm{~min}$, e em razão disso, as médias foram consideradas elevadas..

O Gráfico 02 representa os resultados de todos os pontos de amostragem no período da tarde. Pelo fato de não haver aula no período da tarde no campus Buritis I, as médias em todos os pontos foram consideradas aceitáveis, onde o menor valor de ruído foi registrado no ponto 02, em que há uma área verde (Parque Bandeirante Silva Ortz). As duas ruas principais de acesso principais (José Cláudio Rezende e Paulo Piedade Campus) apresentava-se um tráfego moderado de veículos durante a avaliação de ruído. O Gráfico 03 representa os resultados no período da noite.

No período da noite, observa-se um aumento significativo em todos os pontos de amostragem em relação aos outros períodos do dia. Na última mensuração do ruído da noite, entre $22 \mathrm{~h} 00 \mathrm{~min}$ e $22 \mathrm{~h} 23 \mathrm{~min}$, todos os pontos ultrapassaram o limite estabelecido pela Lei do Silêncio que é de $50 \mathrm{~dB}(\mathrm{~A})$. O ponto de número 7 foi considerado o mais significativo de todos os outros, por causa do número elevado de alunos matriculados no período da noite que frequentam na maior parte das vezes a lanchonete.

Gráfico 01 - Resultados no período da manhã

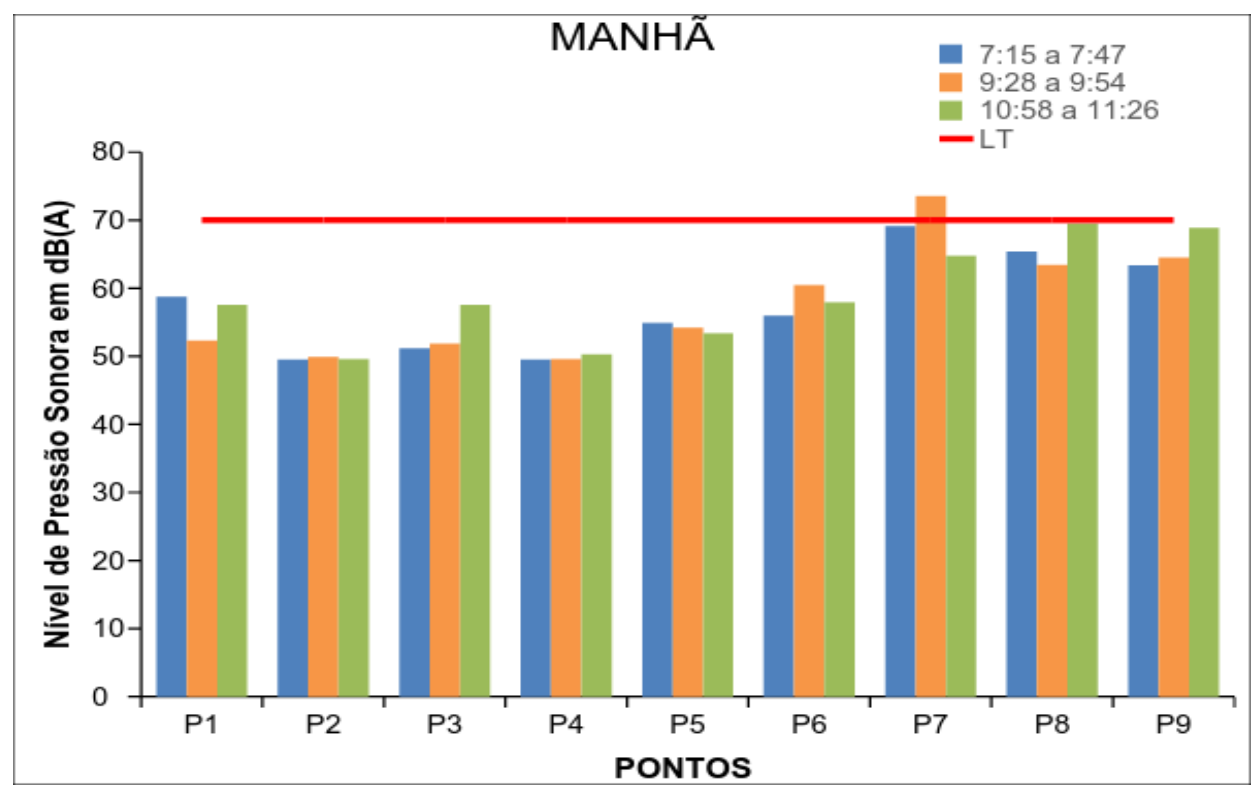

Legenda: P1 (ponto 01); P2 (ponto 02); P3 (ponto 03); P4 (ponto 04); P5 (ponto 05); P6 (ponto 06); P7 (ponto 07); P8 (ponto 08); P9 (ponto 09); LT cor vermelha (Limite de tolerância diurno). 


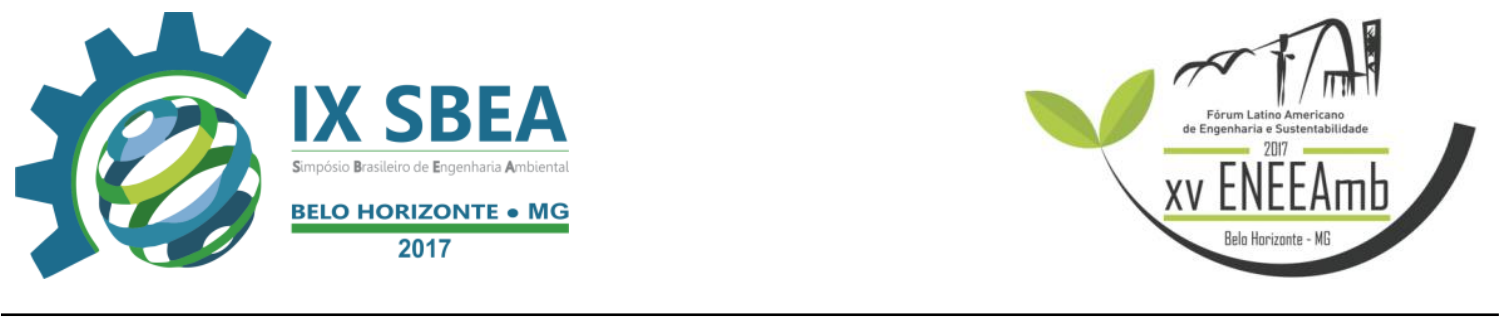

Gráfico 02 - Resultados no período da tarde

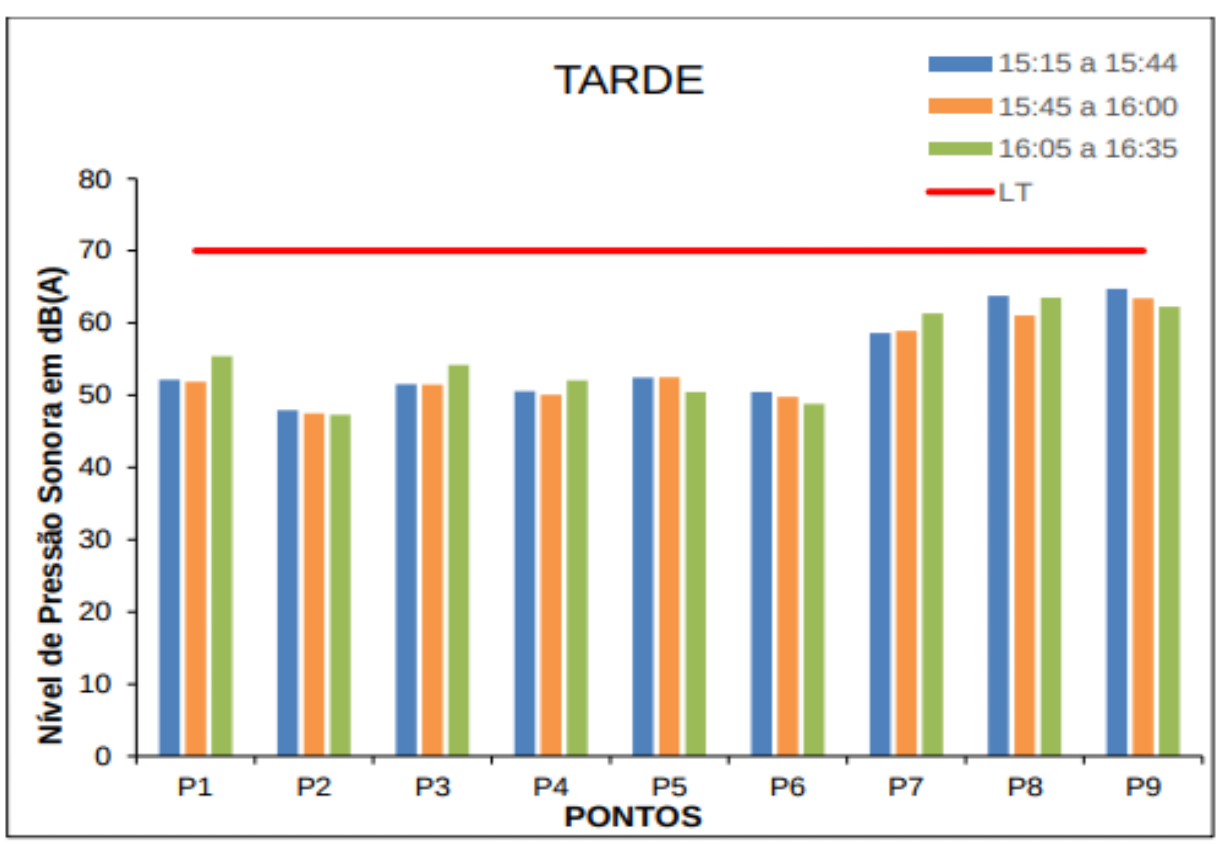

Legenda: P1 (ponto 1); P2 (ponto 2); P3 (ponto 3); P4 (ponto 4); P5 (ponto 5); P6 (ponto 6); P7 (ponto 7);

P8 (ponto 8); P0 (ponto 9); LT - cor amarela (Limite de tolerância período vespertino); LT - cor cinza

(Limite de tolerância período noturno).

Gráfico 03 - Resultados no período da noite

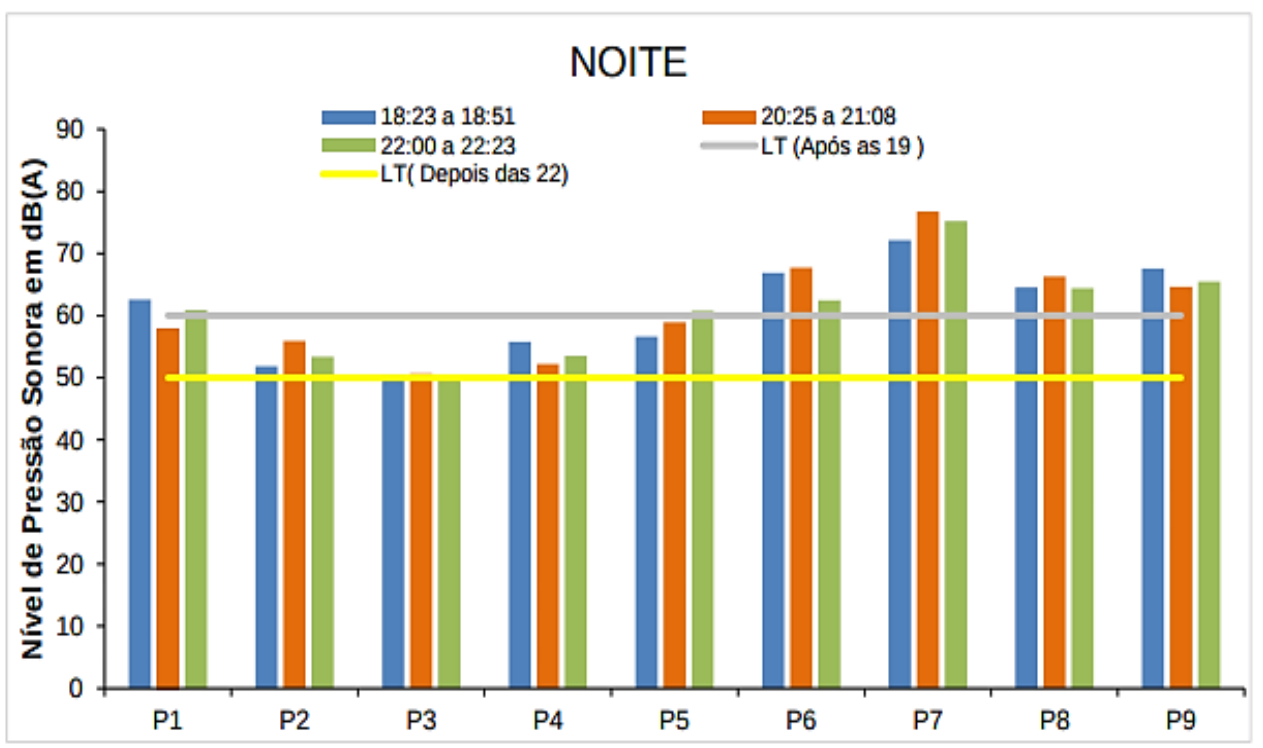

Legenda: P1 (ponto 1); P2 (ponto 2); P3 (ponto 3); P4 (ponto 4); P5 (ponto 5); P6 (ponto 6); P7 (ponto 7);

P8 (ponto 8); P0 (ponto 9); LT - cor amarela (Limite de tolerância período vespertino); LT - cor cinza

(Limite de tolerância período noturno). 


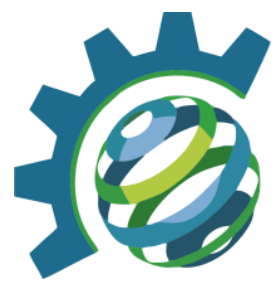

\subsection{Mapa de Ruído do Campus Buritis I}

Para a identificação das áreas consideradas com elevado nível de ruído, a Figura 3 representa o mapeamento de ruído do campus Buritis I, do Centro Universitário Newton Paiva. Observe que, foram selecionadas as faixas de ruído estabelecendo cores específicas. A cor em verde representa as médias do horário do turno da noite (18h30min as 19h00min) cujo intervalo do nível de pressão sonora foi de 30 a $50 \mathrm{~dB}$ (A), o amarelo de 51 a $60 \mathrm{~dB}(\mathrm{~A})$, o laranja de 61 a $70 \mathrm{~dB}$ (A) e para o vermelho de 71 a $90 \mathrm{~dB}(\mathrm{~A})$.

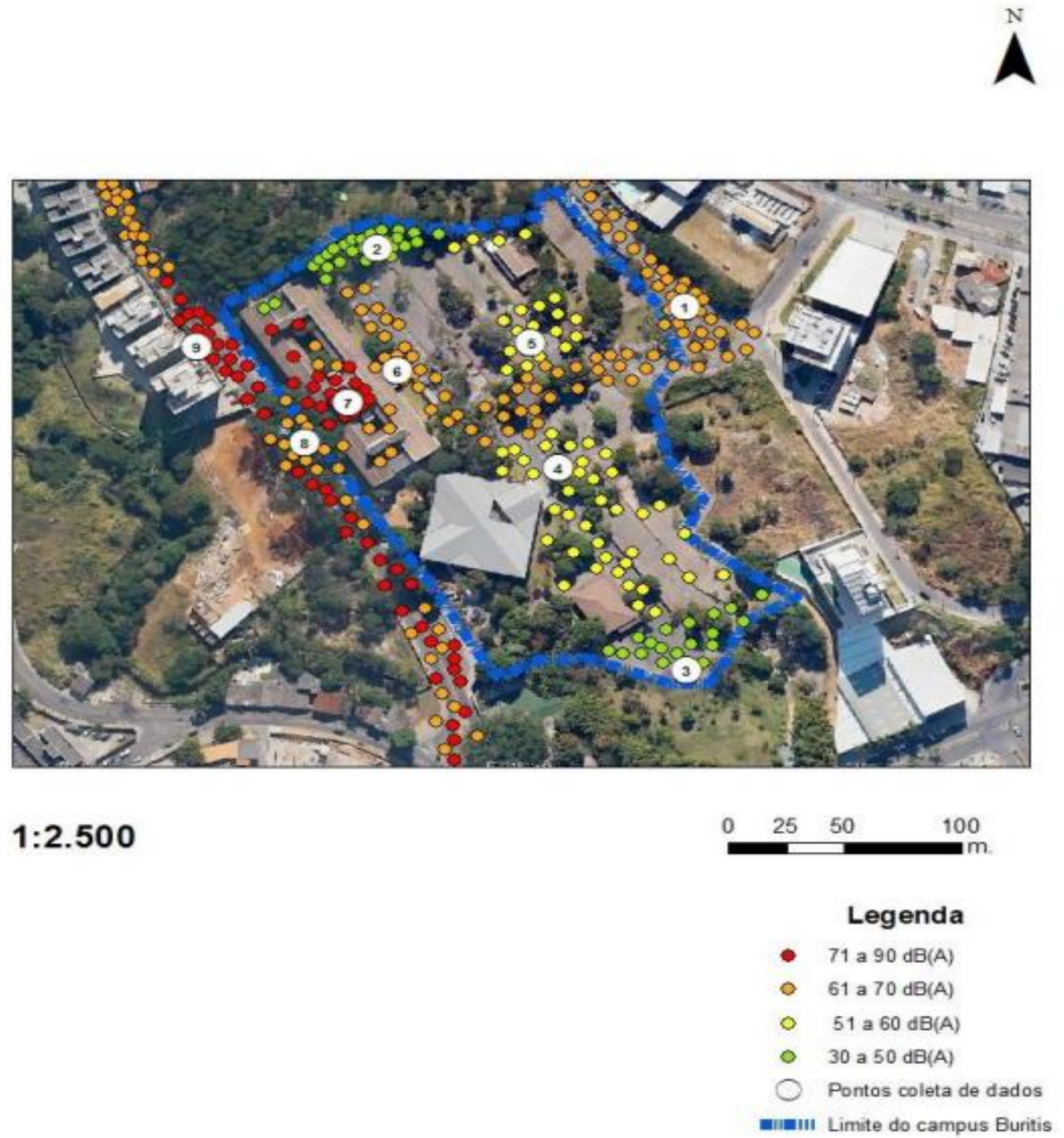

Figura 3 - Mapa de ruído do Centro Universitário Newton Paiva 


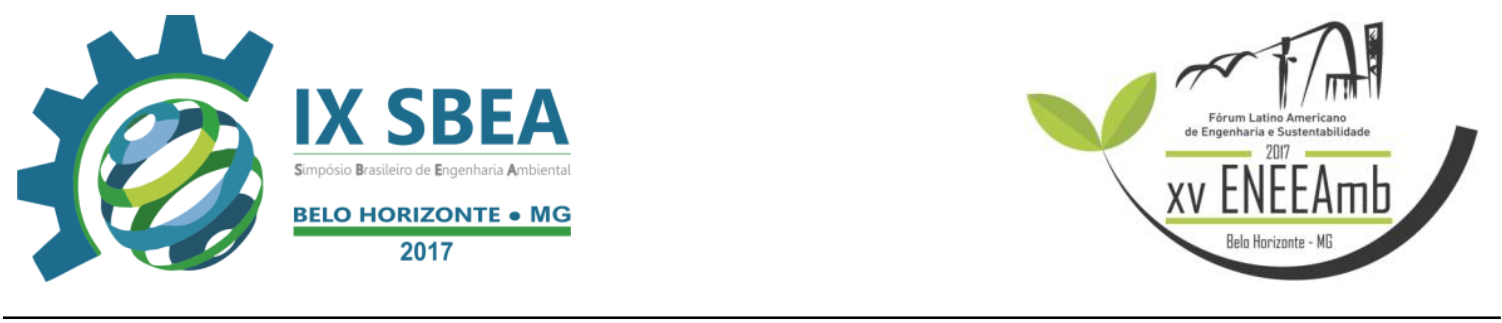

\section{CONCLUSÕES/RECOMENDAÇÕES:}

Com base nos resultados encontrados da avaliação e do mapeamento acústico, pode-se afirmar que a situação do Centro Universitário Newton Paiva é preocupante, com elevados níveis de pressão sonora que ultrapassaram a legislação vigente no município de Belo Horizonte. Tais resultados retratam como ainda evolui cada vez mais a poluição sonora no ambiente urbano, trazendo uma ameaça significativa ao bem-estar e a saúde da população.

Para que se tenha uma boa concentração durante os estudos, é recomendável que os valores de ruído sejam extremamente baixos. É perceptível, então, que os alunos e a comunidade do entorno sintam-se incomodados diante do barulho proveniente dos veículos e pessoas. Logo, o empreendimento do Centro Universitário Newton Paiva necessita implantar, urgentemente, um plano de controle como o elaborado neste trabalho, a fim de se adequar as diferentes normas e legislações.

A manutenção de áreas verdes, como por exemplo, o Parque Municipal Bandeirante Silva Ortz, localizado próximo ao campus Buritis 1 é extremamente importante para o controle do ruído, e foram nestas áreas onde obtivemos os níveis mais baixos de ruído, o que indica conforto acústico para a população do entorno da instituição.

Outras medidas mitigatórias como o incentivo a caronas solidárias, plantio de árvores, instalação do isolamento acústico em janelas e portas em salas de aula, educação no trânsito com a medida de proibição da buzina em locais e horas específicas são fundamentais para amenizar o desconforto causado pelo excesso de ruído no ambiente escolar.

O engenheiro ambiental é o profissional que identifica e avalia a dimensão dos problemas ambientais propondo soluções para controlar estes impactos. O excesso de ruído pode desencadear uma série de danos a nossa saúde, com isso, este profissional deve projetar, implantar e monitorar através de processos de gestão ambiental a melhor maneira de minimizar estes problemas. 


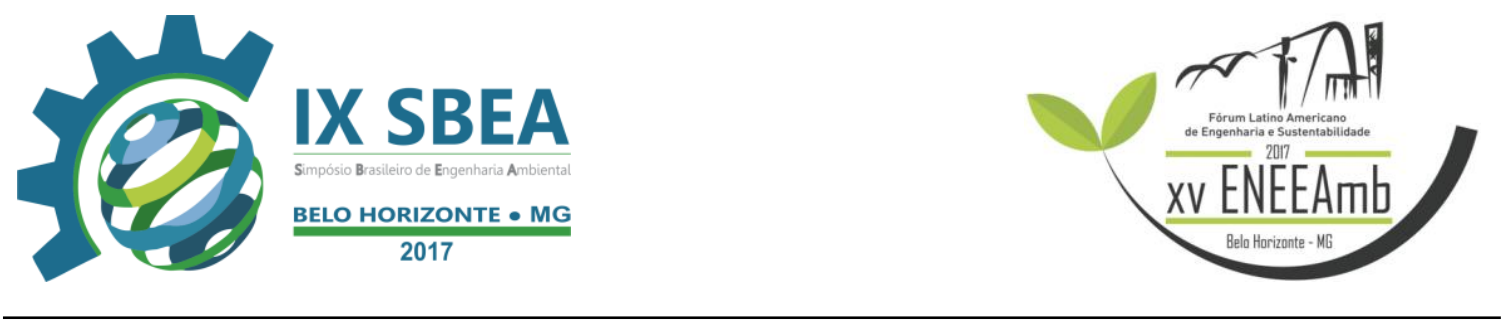

\section{REFERÊNCIAS BIBLIOGRÁFICAS:}

BELO HORIZONTE. Lei Municipal 9505 de 23 de janeiro de 2008. Dispõe sobre o controle de ruídos, sons e vibrações no Município de Belo Horizonte e dá outras providências.

BISTAFA, Sylvio. Acústica aplicada ao controle do ruído. São Paulo: Blucher, $2^{\circ}$ edição, 2011.

CANTIERI, Eduardo et al. Elaboração de um mapa de ruído para a região central da cidade de Curitiba - PR. Produção Online, Florianópolis, 10(1), 71-96, 2010.

CENTRO UNIVERSITÁRIO NEWTON PAIVA. Buritis (Belo Horizonte). Disponível em: <https://www.newtonpaiva.br/complexos/complexo-buritis>. Acesso em: 17 abr. 2017.

NAGEM, Míriam Pompeu. Mapeamento e análise do ruído ambiental: diretrizes e metodologia. Dissertação de Mestrado. Campinas/SP: UNICAMP, Faculdade de Engenharia Civil, 2004, 133p.

PIMENTEL, Bianca Nunes, FEDOSSE, Elenir, RODRIGUES, Nathana da Graça Sartori, CRUZ, Karolline Sérgio, FILHA, Valdete Alves Valentins dos Santos. Percepção do ruído, saúde auditiva e qualidade de vida de professores de escolas públicas. Comunication Research, São Paulo, 21, 1740-1747, 2016.

\section{AGRADECIMENTOS:}

Ao Centro Universitário Newton Paiva pelo suporte durante a realização desta pesquisa. 